\title{
VOZ DE UM MAESTRO: OSWALDO MARKET
}

El destino del maestro es la palabra. No la escritura. Es lo que hace incomparable a Sócrates. Fue un maestro. Habló como sólo puede hacerlo un sabio. Quienes vienen después - Platón el primero -, claro está que siguen hablando, claro que enseñan a quienes les escuchan. Pero, en lo esencial, son ya otra cosa. Una desmesura que no puede ser colmada los separa del verdadero maestro: aquel que, al hablar, impuso un sentido al mundo. Después, la escritura hace sólo ceniza de aquel esplendor primero.

Es lo que enseña el Fedro platónico: hubo saber. En el sentido fuerte - único sentido- de la palabra. Cuando un maestro de Atenas se enfrentó a la común visión de las cosas. Y nada volvió a ser lo mismo. Hubo, después, los discípulos que - carentes del genio y de la generosidad de Sócrates - hicieron con aquello juego: escritura. Dejando, eso sí, claro el testimonio de su deuda. A falta de sabiduría - esa cosa en el límite de lo divino -, hubieron de conformarse con una artesanía bien cuidada, la de escribir, que en nada esencial se diferencia de cualquier otro oficio manual. A eso llama Platón filosofía, arte menor respecto del gran monumento al cual en la voz del maestro asistieron: el de la sofía. Ni está bien ni está mal, ese tránsito de la una a la otra. Sencillamente, cuando no se es - no se puede ya ser - un sabio, se escribe. Para que el tiempo pase. Y, "en lo relativo a la conveniencia del escribir..., según de la manera que se haga, puede ser algo que está bien o que esté mal" (Fedro 274b6-7). Sólo el magisterio es absoluto, porque ningún soporte material tiene más allá de la mente del que escucha.

Son varias las generaciones de filósofos que, en Portugal como en España, han nacido al arte guiados por la voz de un maestro: Oswaldo Market. El cual primó, en el modo absoluto que define a los maestros, la sobria enseñanza oral sobre la vanidosa artesanía del juego de escribir. Su voz permea lo escrito por esas generaciones en ambas lenguas: portugués como español. Es fácil, tan fácil, reconocer a cualquiera de sus discípulos. No en el contenido de lo que éstos piensen o escriban: eso es menor, o incluso despreciable, para un maestro, porque un verdadero maestro no 
busca seguidores, ni siquiera los tolera. Es el estilo el que marca. Cuantos hemos asistido alguna vez a las clases magistrales de Oswaldo Market sabemos eso. Que es lo único que cuenta en filosofía. La irrenunciable primacía ética - porque estética - del estilo.

Que el centro de Filosofía de la Universidad de Lisboa haya recogido ahora en un volumen los textos de Oswaldo Market que forman el volumen A Revolução Kantiana e o Idealismo Alemão ${ }^{1}$ es un acontecimiento académico de primer orden. Porque, en cada línea de esos ensayos que van de Leibniz a Schelling con epicentro en Kant, es la voz del Maestro Market lo que resuena. Viva y abierta como nosotros un día la percibimos, cuando éramos aún jóvenes y él nos abría, ante el espejo de nuestras propias ignorancias, ese espejo frente el cual, sólo frente el cual, puede nacer algo a lo que de un modo serio llamemos filosofía.

He leído esas páginas. Pero no estaba leyendo. Oía la voz del que, por ser maestro, acabó siendo amigo, porque, como Spinoza sabía, sólo la amistad puede unir a los hombres libres. Y todo lo recogido en este libro habla de una sola cosa: libertad. La libertad de un pensamiento al cual la experiencia paradójica de la revolución de 1789 dispara hacia la comprensión de todas las paradojas: de Kant a los jovencísimos Schelling, Hölderlin y Hegel de Tubinga, a través del Fichte de Jena, cuyo mejor lector en la España y el Portugal contemporáneos fuera Oswaldo Market. He encontrado lo que ya sabía que estaba allí, porque lo había oído tantas veces: en las aulas como en las largas sobremesas de Madrid y Lisboa. Y he sabido que lo que queda en el tiempo de esos años son aquellas sobremesas, aquellos relámpagos de magia, en los cuales en la voz de Oswaldo Market resonaba todo el romanticismo alemán. Como resuena ahora en este libro. Con la gravedad imborrable de lo verdadero.

Gabriel Albiac

${ }^{1}$ MARKET, Oswaldo: A Revolução kantiana e o Idealismo Alemão. Lisboa, C.F.U.L., 2011, 397 pp. 